\title{
Neonatal handling induces anovulatory estrous cycles in rats
}

C.M. Gomes ${ }^{1}$, P.J. Frantz ${ }^{1}$ G.L. Sanvitto ${ }^{1}$, J.A. Anselmo-Franci ${ }^{2}$ and A.B. Lucion ${ }^{1}$

\author{
${ }^{1}$ Departamento de Fisiologia, Instituto de Ciências Básicas da Saúde, \\ Universidade Federal do Rio Grande do Sul, Porto Alegre, RS, Brasil \\ ${ }^{2}$ Departamento de Fisiologia, Faculdade de O dontologia de Ribeirão Preto, \\ Universidade de São Paulo, Ribeirão Preto, SP, Brasil
}

\section{Correspondence \\ A.B. Lucion \\ Departamento de Fisiologia ICBS, UFRGS \\ Rua Sarmento Leite, 500 90050-170 Porto Alegre, RS Brasil \\ E-mail: alucion@vortex.ufrgs.br \\ Research supported by FAPERGS, CAPES and CNPq. Publication supported by FAPESP.}

Received April 15, 1999 Accepted July 28, 1999

\section{Abstract}

Since previous work has shown that stimulation early in life decreases sexual receptiveness as measured by the female lordosis quotient, we suggested that neonatal handling could affect the function of the hypothalamus-pituitary-gonadal axis. The effects of neonatal handling on the estrous cycle and ovulation were analyzed in adult rats. Two groups of animals were studied: intact (no manipulation, $\mathrm{N}=10$ ) and handled $(\mathrm{N}=11)$. Pups were either handled daily for $1 \mathrm{~min}$ during the first 10 days of life or left undisturbed. At the age of 90 days, a vaginal smear was collected daily at 9:00 a.m. and analyzed for 29 days; at 9:00 a.m. on the day of estrus, animals were anesthetized with thiopental $(40 \mathrm{mg} / \mathrm{kg}$, ip), the ovaries were removed and the oviduct was dissected and squashed between 2 glass slides. The number of oocytes of both oviductal ampullae was counted under the microscope. The average numbers for each phase of the cycle (diestrus I, diestrus II, proestrus and estrus) during the period analyzed were compared between the two groups. There were no significant differences between intact and handled females during any of the phases. However, the number of handled females that showed anovulatory cycles ( 8 out of 11) was significantly higher than in the intact group (none out of 10). Neonatal stimulation may affect not only the hypothalamus-pituitary-adrenal axis, as previously demonstrated, but also the hypothalamus-pituitary-gonadal axis in female rats.
Infantile experience has long-lasting effects on behavior, as well as on stress reactivity (1-3). In rats, the apparently harmless procedure of handling pre-weaning pups is related to a lesser elevation and a faster return to basal levels of plasma corticosterone in response to a stressor in adult animals (2-4). In terms of reproduction, neonatal handling or stressful stimulation attenuated or prevented the induction of constant diestrus by an unpredictable chronic stress model in adult rats (5).

\section{Key words} - Stress

- Neonatal handling

- Estrous cycle

- O vulation
- Female rat 
tal stress $(10)$ and neonatal handling $(11,12)$ decreased sexual behavior in male and female rats, the aim of the present study was to analyze the effects of handling on the estrous cycle and ovulation as measured by the number of oocytes in the oviduct. We suggest that stimulation early in life would affect not only the hypothalamus-pituitary-adrenal axis, as previously shown $(3,4)$, but also the hypothalamus-pituitary-gonadal axis.

Female Wistar rats were used. From the 1st to the 10th day postpartum, the entire offspring of a mother was submitted to one of the following procedures: pups were left undisturbed (intact animals) or handled. Handling consisted of separating the pups from the mother and gently manipulating them for $1 \mathrm{~min}$. Immediately after being handled, the animals were returned to their mothers in the home cage. In all cases, the number of pups was set at 8 per dam.

After weaning, only 1 female from each offspring group was randomly chosen as an experimental subject. These females were separated and housed in groups of 2-5 per cage $(41 \times 34 \times 17 \mathrm{~cm})$ according to body weight at room temperature of $22 \pm 1{ }^{\circ} \mathrm{C}$ under a light-dark cycle (lights on from 7:00 a.m. to 7:00 p.m.). Rodent chow (Nuvilab $\mathrm{Cr} 1$, Colombo, PR, Brazil) and water were

Figure 1 - Distribution of female rats according to the number of oocytes on the day of estrus. Each symbol represents an animal. Intact control rats were kept undisturbed during the neonatal period; handled animals were gently manipulated for $1 \mathrm{~min}$ daily from the 1st to the 10th day after delivery. After collection of vaginal smears for 29 days, the animals were anesthetized at 9:00 a.m. on the day of estrus, when ovaries were removed and the number of oocytes was counted.

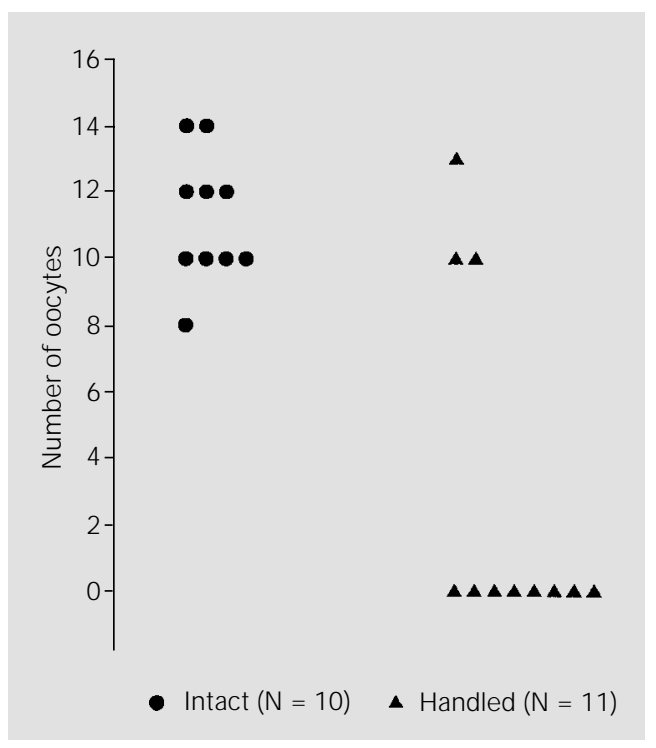

available at all times.

At the age of 90 days, females were kept 1 per cage and divided into 2 groups according to the procedure during the neonatal period, i.e., intact $(\mathrm{N}=10)$ and handled $(\mathrm{N}=$ 11). The same animals in each group were used to observe the estrous cycle and to measure the number of oocytes. A vaginal smear was collected daily at 9:00 a.m. and analyzed under the microscope for 29 days; at 9:00 a.m. on the next estrus day, animals were anesthetized with thiopental $(40 \mathrm{mg} /$ $\mathrm{kg}$, ip), the ovaries were removed and the oviduct was dissected and squashed between 2 glass slides. The number of oocytes of both oviductal ampullae was counted under the microscope. The mean ( \pm SEM) frequency of diestrus I, diestrus II, proestrus and estrus during the 29 days was compared between the 2 groups by the Student $t$-test. The median (interquartile range) number of oocytes was compared between the 2 groups by the Mann-Whitney U-test. In all cases, the significance was set as $\mathrm{P}<0.05$.

Neonatal handling had no effect on the mean frequency of each phase of the cycle as compared to intact females. Analysis of the estrous cycles of each female during the 29day period showed their regularity. Figure 1 presents the distribution of the animals of both groups concerning the number of oocytes. The median number (interquartile range) of oocytes in handled females $[0(0 /$ 13)] was significantly lower than in intact ones [11(10/12)].

The results showed that neonatal stimulation (handling) reduced the reproductive capability of females by blocking ovulation in most animals although the estrous cycle remained regular.

It is well established that, in rats, ovulation induction requires a sharp surge of gonadotrophins and prolactin in the pre-ovulatory period that depends on the positive feedback of estrogens (13). The mechanism by which the estrogens stimulate the surge in luteinizing hormone-releasing hormone 
(LHRH) remains unclear. Recent reports suggest that estrogens may not act directly on LHRH neurons, but may increase the activity of noradrenergic neurons $(14,15)$. In fact the activation of the noradrenergic nuclei A1, A2 and A6 of the locus coeruleus has been related to estrogen and LHRH secretion. Moreover, estrogen level during the estrous cycle is associated with the expression of FOS protein in the A1 nucleus (15). Locus coeruleus projects to the preoptic area and to the suprachiasmatic nucleus, which are involved in the regulation of cyclic secretion of hormones in the anterior pituitary $(16,17)$. Luteinizing hormone and prolactin surge (16), as well as secretion of corticotrophin releasing hormone (18) are dependent on noradrenergic inputs. Electrolytic lesions of the locus coeruleus on the morning of proestrus decrease the content of norepinephrine in the medial preoptic area and medial basal hypothalamus and block the pre-ovulatory surge of gonadotrophins and therefore ovulation (16). On the other hand, microdialysis experiments have demonstrated that the stimulation of A1 and A2 nuclei increases norepinephrine levels in the preoptic area, which is the site of LHRH synthesis (19).

The results of the present study showing that handled females had regular, but anovulatory estrous cycles, indicate that ovarian steroids produced during the pre-ovulatory period were effective in exerting their peripheral effects, as indicated by the regular changes in the vaginal mucosa. However, since the central effects of estrogens were apparently altered by neonatal handling, we suggest that stimulation early in life may affect neural substrates that modulate the hypothalamus-pituitary-gonadal axis. The central noradrenergic system could be one of the neural systems altered by neonatal stimulation. It seems likely that the central noradrenergic system is not responding properly to peripheral estrogen, leading to a dysfunction in luteinizing hormone secretion that might explain the anovulatory cycles in the rats. Experiments are being carried out in our laboratories to test this hypothesis.

Studies on adult behavior and neuroendocrine effects of neonatal stimulation have focused on stress-related events and the results have led to the conclusion that stimulation early in life may alter neural systems that modulate the hypothalamus-pituitaryadrenal axis $(3,9,20)$. Indeed, in animals submitted to neonatal stimulation, the increased efficacy in suppressing the activity of the hypothalamus-pituitary-adrenal axis after stress in adulthood appears to be related to the increased population of glucocorticoid receptors in the hippocampus and frontal cortex. Likewise, central modulation of the hypothalamus-pituitary-gonadal axis may also be altered by neonatal stimulation.

In conclusion, the present results show that neonatal handling may induce long-lasting and stable changes in the hypothalamuspituitary-gonadal axis of adult female rats, causing reduced reproductive capacity.

\section{References}

1. Denenberg VH \& Smith SA (1963). Effects of infantile stimulation and age upon behavior. J ournal of Comparative and Physiological Psychology, 56: 307-312.

2. Levine S, Haltmeyer GC, Karas GG \& Denenberg VH (1967). Physiological and behavioral effects of infantile stimulation. Physiology and Behavior, 2: 55-59.

3. Liu D, Diorio J , Tannenbaum B, Caldjii C,
Francis D, Freedman A, Sharma S, Pearson D, Plotsky PM \& Meaney MJ (1997). Maternal care, hippocampal glucocorticoid receptors, and hypothalamicpituitary-adrenal response to stress. Science, 277: 1659-1662.

4. Plotsky PM \& Meaney MJ (1993). Early, postnatal experience alters hypothalamic corticotropin-releasing factor (CRF)
mRNA, median eminence CRF content and stress-induced release in adult rats. Molecular Brain Research, 18: 195-200.

5. Gonzalez AS, Rodriguez Echandia EL, Cabrera R \& Foscolo MR (1994). Neonatal chronic stress induces subsensitivity to chronic stress in adult rats: II. Effects on estrous cycle in females. Physiology and Behavior, 56: 591-595. 
6. McEwen BS (1994). How do sex and stress hormones affect nerve cells? Annals of the New York Academy of Sciences, 743: 1-16.

7. McLusky NJ \& Naftolin F (1981). Sexual differentiation of the central nervous system. Science, 211: 1294-1303.

8. Rosenfeld $P$, Suchecki $D \&$ Levine $S$ (1992). Multifactorial regulation of hypothalamic-pituitary-adrenal axis during development. Neuroscience and Biobehavioral Reviews, 16: 553-568.

9. Meaney $\mathrm{MJ}$, Diorio J, Francis D, LaRocque S, O'Donnell D, Smythe J W, Sharma S \& Tannenbaum B (1994). Environmental regulation of the development of glucocorticoid receptor systems in the rat forebrain. Annals of the New York Academy of Sciences, 746: 260-273.

10. Ward I (1972). Prenatal stress feminizes and demasculinizes the behavior of males. Science, 175: 82-84.

11. Frantz PJ , Gomes CM \& Lucion AB (1998). Efeito da estimulação neonatal sobre o comportamento sexual de ratas. X Salão de Iniciação Científica da Universidade Federal do Rio Grande do Sul, October
19-23, Porto Alegre, RS, Brazil, 225 (Abstract).

12. Lucion AB, Cadore LP, Charchat $H$, Barros HMT \& Padoin MJ (1997). Effects of noxious stimulation during the stress-hyporesponsive period on behaviors of pre-pubertal and adult male and female rats. 27th Annual Meeting of the Society for Neuroscience, October 25-30, New Orleans, LA, USA, 1081 (Abstract).

13. Freeman ME (1994). The ovarian cycle of the rat. In: Knobil E \& Neill J (Editors), The Physiology of Reproduction. Raven Press, New York.

14. Anselmo-Franci J A \& Oliveira M (1996). Control of prolactin secretion by the locus coeruleus in cycling female and male rats. ICE '96. 10th International Congress of Endocrinology, J uly 12-15, San Francisco, CA, USA, 308 (Abstract).

15. J ennes $L$, J ennes $M E$, Purvis $C \&$ Nees $M$ (1992). c-Fos expression in noradrenergic A2 neurons of the rat during the estrous cycle and after steroid hormone treatments. Brain Research, 586: 171-175.

16. Anselmo-Franci J A, Franci CR, Krulich L, Antunes-Rodrigues J \& McCann SM
(1997). Locus coeruleus lesions decrease norepinephrine input into the medial preoptic area and medial basal hypothalamus and block the $\mathrm{LH}, \mathrm{FSH}$ and prolactin preovulatory surge. Brain Research, 767: 289296.

17. J ones BE \& Moore RY (1977). Ascending projections of the locus coeruleus in the rat. Autoradiographic study. Brain Research, 127: 23-53.

18. Plotsky PM (1987). Facilitation of immunoreactive corticotropin-releasing factor secretion into the hypophyseal-portal circulation after activation of catecholaminergic pathways or central norepinephrine injection. Endocrinology, 121: 924930.

19. Fernández-Galaz C, Dyer RG \& Herbison AE (1994). Analysis of brainstem Al and A2 noradrenergic inputs to the preoptic area using microdialysis in the rat. Brain Research, 636: 227-232.

20. Meaney MJ \& Aitken DH (1985). The effects of early postnatal handling on hippocampal glucocorticoid receptor concentrations: Temporal parameters. Developmental Brain Research, 22: 301-304. 